\title{
ASSESSMENT OF CLIMATE CHANGE EFFECTS TO PRECIPITATION PATTERNS USING STATISTICAL PROCESS CONTROL METHODS
}

\author{
VUCIJAK, B[ranko]; MIDZIC KURTAGIC, S[anda]; CERIC, A[dmir]; \\ KUPUSOVIC, T[arik] \& SPAGO, S[uad]
}

\begin{abstract}
There is a number of reports underlining ongoing temperature increase and precipitation pattern change in the world during the last decades. This paper presents the application of the statistical process control (SPC) methods to check whether the present changes are "statistically expected". The method is based on the comparison of the precipitation patterns from the 1961-1990 reference period with the recent precipitations from the 2000-2010 period in the Bihac area in Bosnia and Herzegovina. It can be inferred that the monthly precipitation patterns have changed; the minimum precipitation is shifted from January to July and the maximum from late autumn to late summer. Applying the criteria often used in the SPC methods for the assessment of "out of control" situations, it may be inferred that the observed changes in the total monthly precipitation are statistically expected.

Keywords: statistical process control, control charts, process capability, climate change, climate variations
\end{abstract}

\section{INTRODUCTION}

Climate is conveniently defined as the "average weather for a particular region and time period, including temperature, precipitation, humidity, sunshine, cloudiness, and wind, usually taken over 30-years" [1]. It is an average pattern of weather for a particular region. It has changed many times during the past of the Earth, usally in response to natural causes, e.g. due to interaction between the sun, land, oceans and atmosphere, so as the effects that they have on each other. The term "climate change" refers to changes in the climate caused by human activities, mostly during the $20^{\text {th }}$ and $21^{\text {st }}$ century. Specially underlined is the so called "greenhouse effect", a process by which thermal radiation from a planetary surface is absorbed by atmospheric greenhouse gases, and is re-radiated in all directions. Part of infrared radiation is trapped by gases in the air and re-radiated back towards the surface, also with the warming effect, resulting with the higher average surface temperature than it would be if heating by solar radiation were the only warming mechanism. Such gases are referred to as greenhouse gases.

The „Climate Change 2007: Synthesis Report“ writes that the temperature increase is widespread over the globe and is greater at higher northern latitudes, e.g. average Arctic temperatures have increased at almost twice the global average rate in the past 100 years. Observations during the last 50 years show that the average temperature of the global ocean has increased down to depths of at least 3,000 $\mathrm{m}$ and that the ocean has been taking up over $80 \%$ of the heat being added to the climate system [2]. But there is debate if it relates to human induced climate effect, or is it another climate variation not being caused by human behaviour.
It is foreseen that nearly all European regions will be adversely affected by the climate change, and this situation will create new challenges to many economic sectors in the future. The questions rise whether some of these changes are statistically expected (including the way to define what may be statistically expected) and whether the water regime is really changed in a way it makes a completely different pattern as compared to the previous meteorologically significant period. These questions are addressed in the present paper using an approach based on the statistical process control.

\section{USE OF STATISTICAL PROCESS CONTROL}

During 1920s Walter Shewhart developed the basic theory of statistical process control (SPC) [3], which was widely popularised at the later time by Edwards Deming [4]. They noticed that the repeated measurements of a single process will show some level of variation. If the process is stable, its variation will be predictable and it is possible to describe it with statistical distributions, among which normal distribution is most frequently used. The SPC methods are used today for different problems like healthcare [5], software processes [6], statistical inference at work [7] and others; however, its use for environmental processes is still limited.

The main assumption of the method is that the inherent nature of any process has some common cause variations, which cannot be altered without changing the process itself. However, there are additional causes of variations, called 'assignable' or 'special', which represent unusual disruptions to the process, the causes of which should be removed after being recognized. The SPC aims to distinguish between these two types of variation, thus to avoid both over-reaction and underreaction or lack of needed response to the process [8].

The main principle of statistical process control is to make distinction of the process variation causes - while random variations are inherent to the process and they can be removed only by changing the entire process, other causes of variation, relatively large in magnitude and identifiable, are conveniently classified as 'assignable' or 'special' causes. When such causes of variation are present, the process is classified as 'unstable' or 'out of statistical control'.

Therefore the SPC tries to provide answers to the following key questions: (1) "Is the process under control?", and (2) "What is the extent of the process variability?". The answers depend on the presence of any special sources of variation - if they are not present the 
variability is due only to the natural process capability, i.e. only common sources of variation are present.

To control a process using data, one needs to monitor the current state of the accuracy and precision of the distribution of the data, what is typically done using control charts. A control chart can be conveniently compared with a traffic signal - green light is given when the process is running properly and does not need any adjustments (process is under control), meaning that only common causes of variation are present. Next level is amber light, which signals that some discrepancy to the natural process might be present. Red light clearly shows that assignable or special cause(s) of variation appeared before the occurrence of such data and the process is definitely out of control. But such control mechanism may be used only when the process itself is "in statistical control", meaning that it did not change its main behaviour characteristics, such as the mean or the variance. It was foreseen that such an approach would be primarily used in production processes, and so far it has been rarely applied for the assessment of natural processes (e.g. [9]).

\section{SPC I-CHART FOR PRECIPITATION DATA}

The simplest variable chart which may be used is one for individual measurements, the so-called "i-chart". The i-chart is often used with one-at-a-time data and the individual values, not means of samples. The i-chart is simple and indicates changes in the mean level (accuracy or centring). With careful attention, the i-chart will even indicate changes in variability; however, it is not so good at detecting small changes in process centring [10].

The control chart used within this paper is a variation of the i-chart of data samples. The centreline (CL) is placed at the mean of the past performance, the action lines (upper and lower, UAL and LAL) are placed at three standard deviations (SE) from the centreline. The warning lines (UWL and LWL) are placed at two standard deviations from the sample means. If the process is stable, it may be expected that most of the individual values lie within the range $X \pm 3 S E$ [10], based on the assumption of the normal data distribution.

When plotting the individual results on the i-chart, the rules for "out of control" situations are the following:

1. any points falling outside the $3 \mathrm{SE}$ limits;

2. two out of three successive points are outside the 2 SE limits;

3. eight points in a run on one side of the mean.

Due to relative insensitivity of the i-charts, horizontal lines at $\pm 1 \mathrm{SE}$ on either side of the mean may be presented as well. It might be considered that the process is out of control if four of five points plot outside these limits [8]. This situation will not be addressed here.

This research is based on precipitation data from the Bihać meteorological station in Bosnia and Herzegovina (Fig. 1). The data were recorded by the Federal Meteorological Institute, and are valid. The available data cover two periods: 1961-1990 and 2000-2010. The gap of the period 1991-1999 is due to the war activities in $\mathrm{B} \& \mathrm{H}$, thus the second data set is significantly smaller.
Twelve data sets were established for each period based on the total monthly precipitation ( $\mathrm{mm} / \mathrm{month})$., The arithmetic mean (CL) and standard deviations (SE) are calculated for each of the months and for each of the two research periods, 1961-1990 and 2000-2010. The mean and standard deviation for the period from 1961-1990 were used to prepare the related control chart, whereas the data from 2000-2010 were assessed whether they are still "under control". That is, the control chart presents the total monthly precipitation for the period 2000-2010, and uses the same warning and action lines established for the data of the period 1961-1990, in order to evaluate the level of its variations.

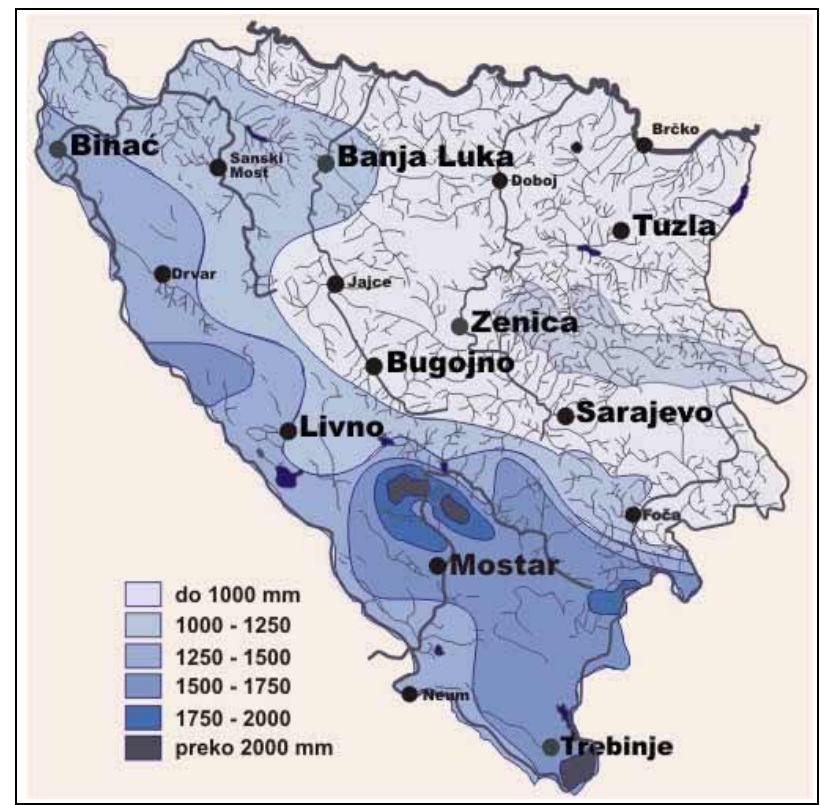

Fig. 1.Annual precipitation in Bosnia and Herzegovina (Source: Federal Meteorological Institute)

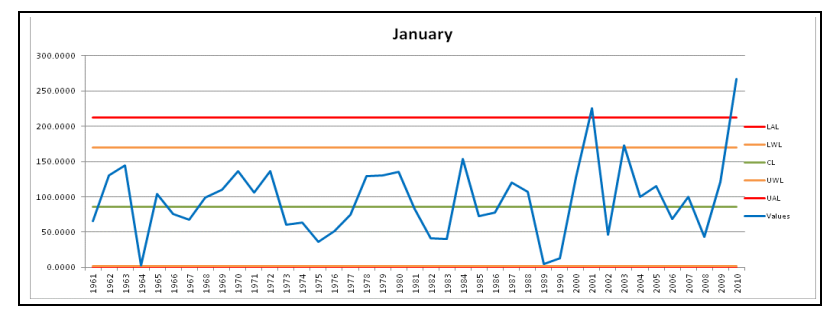

Fig. 2. i-chart for precipitations - January

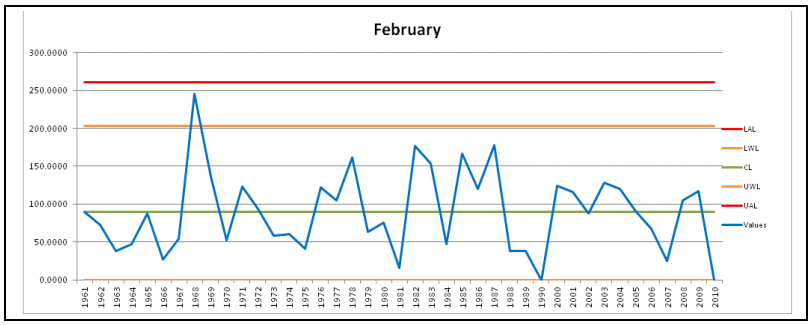

Fig. 3. i-chart for precipitations - February

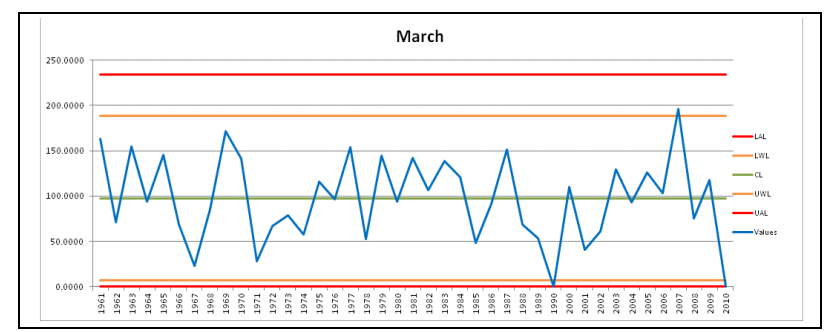

Fig. 4. i-chart for precipitations - March 


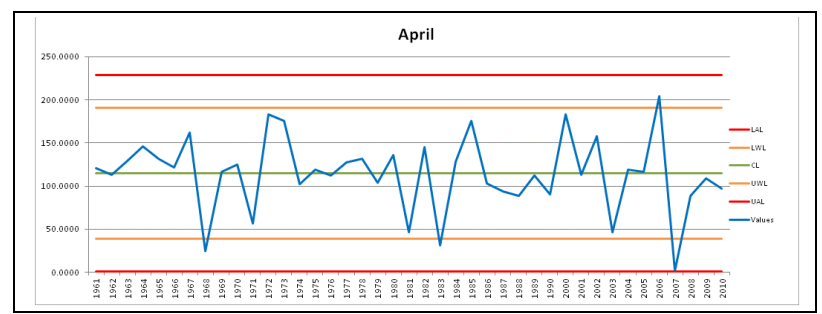

Fig. 5. i-chart for precipitations - April

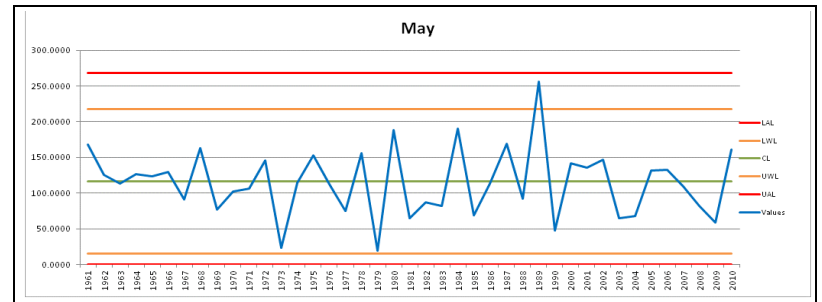

Fig. 6. i-chart for precipitations - May

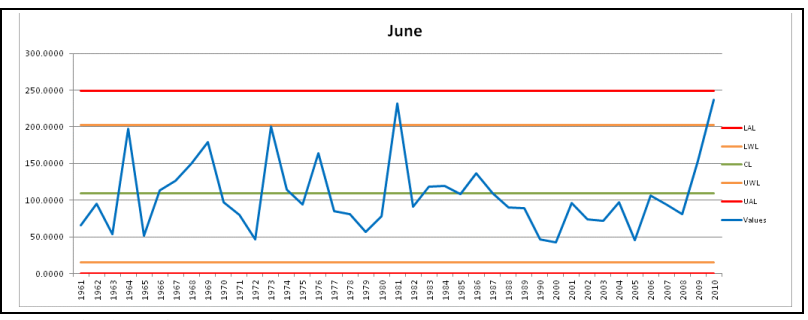

Fig. 7. i-chart for precipitations - June

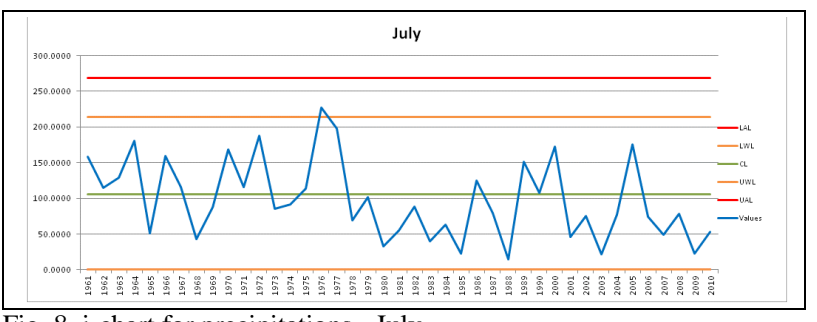

Fig. 8. i-chart for precipitations - July

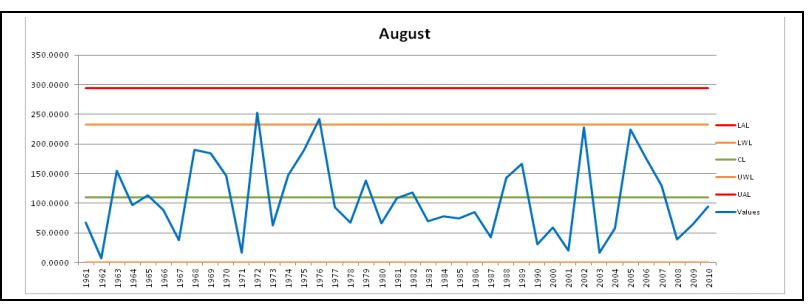

Fig. 9. i-chart for precipitations - August

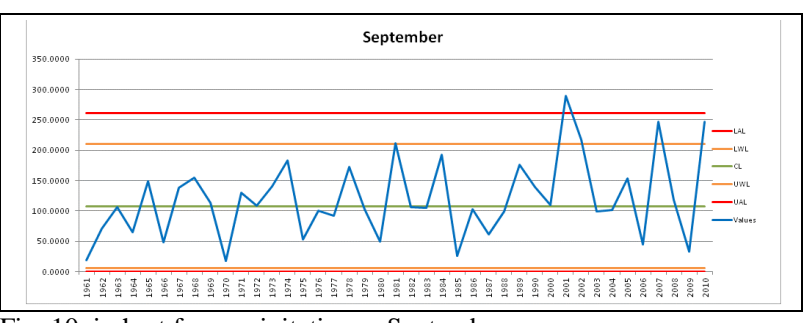

Fig. 10. i-chart for precipitations - September

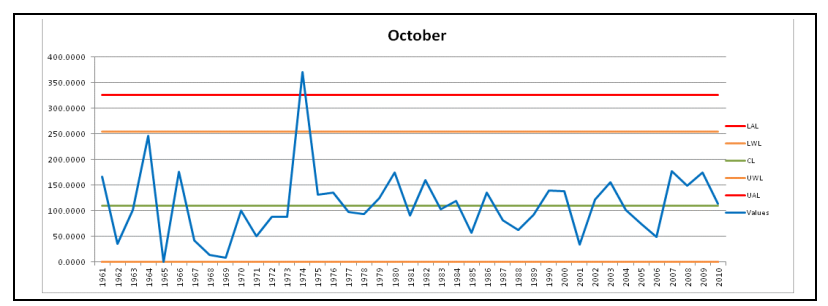

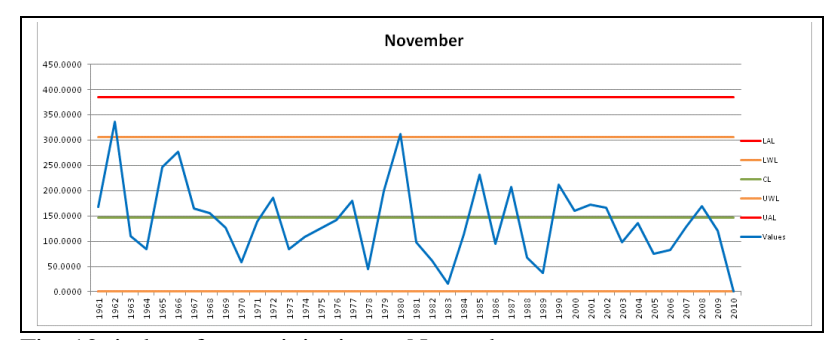

Fig. 12. i-chart for precipitations - November

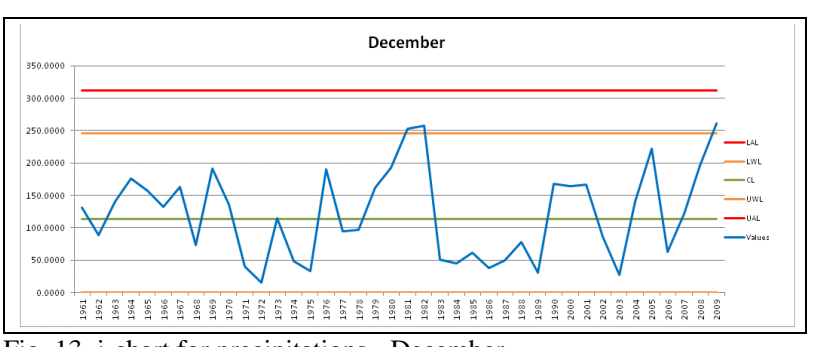

Fig. 13. i-chart for precipitations - December

\section{ASSESSMENT OF CONTROL CHARTS}

The monthly precipitation over the research period for each month in the year is presented in the control charts on Fig. 2-13. Based on the previously mentioned rules, it can be inferred from the graphs whether the new precipitation pattern relating to the period from 20002010 is "out of control". In this case we may also say that the pattern is statistically expected.

When observing only the period 2000-2010 by months, it may be observed that only January 2010 (Fig. 2) and September 2001 (Fig. 10) fall under the criterion outside 3 SE limits. It may also be noticed that the total precipitation in June during 2000-2008 is always below the Center Line. Applying this test only, it may be inferred that the changes in the total monthly precipitation are statistically expected, except in few months mentioned earlier.

It can be observed that the average monthly precipitation has changed between the two research periods in all twelve data samples (months). An increase is particularly high for January (Fig. 2), September (Fig. 10) and December (Fig. 13), and the decline for July (Fig. 8) and November (Fig. 12). In other months this change is below $10 \%$, and can be considered negligible.

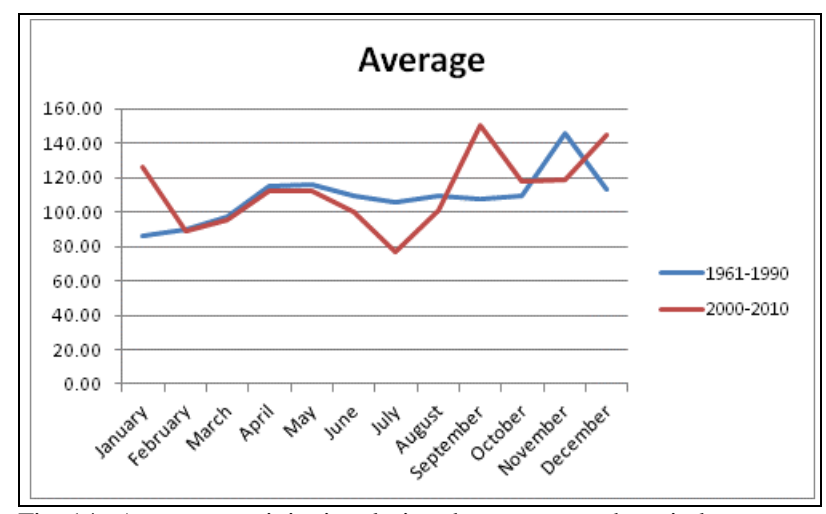

Fig. 14. Average precipitation during the two research periods

These changes are not related to any significant increase or decline in the total annual precipitation - the average of the average monthly precipitation during the period from $1961-1990$ is $108.831 / \mathrm{m}^{2}$, whereas the 
average for the period 2000-2010 totals $112.12 \mathrm{l} / \mathrm{m}^{2}$. These sums indicate that the annual precipitation has not significantly changed between the two periods; however, the redistribution of precipitation between the months is present (Fig. 14). A significant alteration in the precipitation patterns can be observed in the periods from July-January, where the minimum precipitation is shifted from January to July. This pattern can be observed on the i-chart for July (Fig. 8). The maximum precipitation is shifted from late autumn to late summer (AugustSeptember).

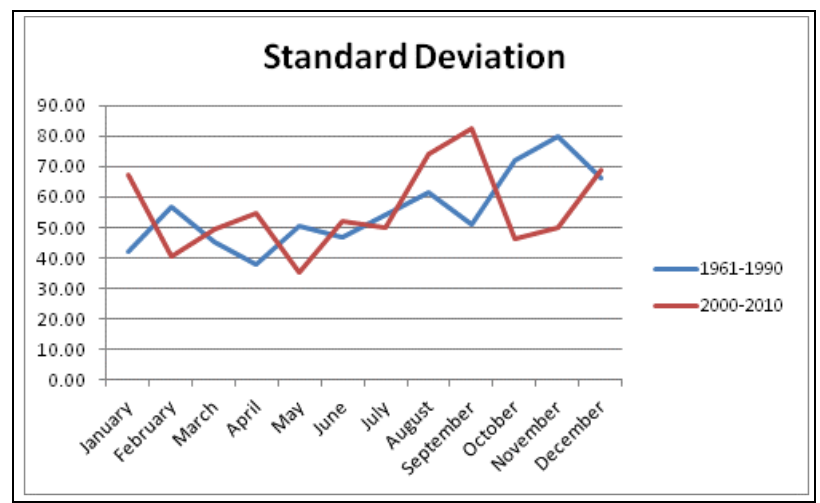

Fig. 15. Standard deviation of the data during the two research periods

Shifts in the precipitation patterns are also assessed by standard deviation, which is related to interannual variations of the total monthly precipitation. An increase in the period from 2000-2010 may be observed for January, April, August and September, whereas in February, May, October and November standard deviation declined (Fig. 15). An increase is particularly important, as it may indicate that more severe precipitation events take place.

Looking also at the control charts for these months, it may be stated that the monthly precipitation was much more variable in January, August and September during the latter research period, whereas the increase in the SE for April is mainly due to events from 2006 and 2007. Decline in the SE for February, May and November is accompanied by the decline in the average precipitation.

\section{CONCLUSION}

The paper presents practical usability of the one of the SPC methods for the evaluation of the climate change effects to the precipitation patterns. The method in this paper is based on the comparison of the precipitation patterns from the 1961-1990 reference period with the recent precipitations from the 2000-2010 period, using ichart. It can be inferred that the monthly precipitation patterns have changed; however, they should not necessarily be classified significant, since most of the variations can be considered statistically expected according to the method.

The method provides a relatively simple tool for the assessment of the variation in the precipitation patters, which is the major advantage that makes the method very useful for decisionmakers in the water sector. For example, the observed precipitation variations in winter months (November to January) should be taken into account when preparing or updating strategic or annual plans for hydro-power reservoir management or river basin management in general. This conclusion may be confirmed with example of several large floods that were recorded in $\mathrm{B} \& \mathrm{H}$ in recent years during December and January, which had not been prevented by appropriate necessary management actions since such change in precipitation patterns was not recognized and thus was not taken into account when planning reservoir management.

The drawback is that changes in standard deviations show that such precipitation pattern change is not stable, since higher standard deviation variations indicate wider range of statistically expected values. This is for example clearly visible at the control charts for September or December where the variations of the total montly precipitation during the 2000-2010 period are higher then in the former period, and are also higher then in other months of the year.

As the SPC method has rarely been used for the assessment of natural processes, further research will be undertaken to verify the applicability of the method for the assessment of the climate change effects. Specifically, it should be tested for data not only of other locations or or areas but also of or types like temperatures, sea level, water flow or water level at rivers, lengths of dry periods, etc. i-chart used in this paper is just one possible type of control charts, and other types should be tested too, underlining mean and range control charts.

\section{REFERENCES}

[1] NASA - National Aeronautics and Space Administration (2005). What's the Difference Between Weather and Climate?, available at http://www.nasa.gov/mission_pages/noaan/climate/climate_weather.html (accessed on July 7, 2012)

[2] IPCC (2007). Climate Change 2007: Synthesis Report, Contribution of Working Groups I, II and III to the Fourth Assessment Report of the Intergovernmental Panel on Climate Change [Core Writing Team, Pachauri, R. K., and Reisinger, A. (eds.)], Geneva, Switzerland

[3] Bayart, D. (2001). Walter Andrew Shewhart, Statisticians of the Centuries (ed. C. C. Heyde and E. Seneta) pp. 398-401. New York: Springer

[4] Thompson, J. R. and Koronacki J. (2002). Statistical Process Control: The Deming Paradigm and Beyond. Chapman \& Hall/CRC, USA, ISBN 1-58488-242-5

[5] Benneyan, J. C., Lloyd, R. C., Plsek, P. E. (2003). Statistical process control as a tool for research and healthcare improvement, Qual Saf Health Care, Vol. 12, pp. 458-464

[6] Jalote, P., Saxena, A. (2002). Optimum Control Limits for Employing Statistical Process Control in Software Process, IEEE Transactions on Software Engineering, Vol. 28, No. 12, pp. 11251133

[7] Bakker, A., Kent, P., Derry, J., Noss, R., Hoyles, C. (2008). Statistical Inference at Work: Statistical Process Control as an Example, Statistics Education Research Journal, 7(2), pp. 130145

[8] Woodall, W. H. (2000). Controversies and Contradictions in Statistical Process Control. Journal of Quality Technology, Vol. 32, No. 4, pp. 341-350

[9] Vucijak, B., Kupusovic, T., Midzic-Kurtagic, S., Ceric, A. (2012). Applicability of Assessment of Climate Change by Statistical Process Control Methods. Proceedings of SDEWES 2012 Conference, Ohrid, July 1-7, 2012

[10] Oakland, J. S. (2003). Statistical Process Control, Fifth Edition. Butterworth-Heinemann, An imprint of Elsevier Science, Burlington MA, USA, ISBN 0-7506-5766-9 